\title{
Superação de dormência em sementes de três espécies de Ipomoea
}

\author{
Overcoming dormancy seed in three Ipomoea species
}

\author{
Daiana Pazuch ${ }^{\mathrm{I}}$ Michelangelo Muzell Trezzi ${ }^{\mathrm{I}}$ Francielli Diesel $^{\mathrm{I}}$ \\ Marcos Vinícius Jaeger Barancelli ${ }^{I}$ Sorhaila Camila Batistel ${ }^{\mathrm{I}}$ Renato Pasini $^{\mathrm{I}}$
}

\section{RESUMO}

\begin{abstract}
Oconhecimento do método desuperaçãodedormência mais adequado para cada espécie auxilia na identificação do tipo de dormência, bem como na definição de estratégias de manejo que permitam o controle mais eficaz. As espécies do gênero Ipomoea encontram-se amplamente distribuidas nos estados brasileiros, as mais comumente encontradas em lavouras de soja na região Sudoeste do Paraná são I. purpurea, I. indivisa e I. grandifolia. Assim, neste trabalho, o objetivo foi selecionar métodos eficazes de superação da dormência nas espécies Ipomoea indivisa, I. grandifolia e I. purpurea e determinar como eles influenciam na cinética da germinação das sementes dessas espécies. Os tratamentos utilizados foram água quente, escarificação mecânica, escarificação mecânica + resfriamento, escarificação química e testemunha. Na avaliação do efeito dos tratamentos, determinou-se a porcentagem de germinação, tempo médio, índice de velocidade e frequência relativa de germinação. A escarificação com ácido sulfúrico incrementou a germinação das sementes de I. indivisa e I. purpurea e o indice de velocidade de germinação àquelas de I. purpurea. O tratamento com água quente foi o mais eficiente em promover a germinação das sementes de I. grandifolia, e em reduzir o tempo médio de germinação das sementes de I. grandifolia e I. purpurea, de forma que, nos tratamentos de superação de dormência, há sincronização do processo de germinação.
\end{abstract}

Palavras-chave: corda-de-viola, germinação, vigor, planta daninha.

\section{ABSTRACT}

The knowledge of the method of overcoming dormancy for each species helps in identification of dormancy type and to outline the most appropriate management strategies for effective control measures. The species of the genus Ipomoea are widely distributed in the Brazilian states, the most commonly found in soybean crops in the Southwest region of Paraná are I. purpurea, I. indivisa and I. grandifolia. In this research the aim was select methods of overcoming seed dormancy for species Ipomoea indivisa, I. grandifolia and I. purpurea, and determine how these methods influence the kinetic germination of these species. The treatments consisted of hot water, chiseling, chiseling plus cooling, chemical scarification and control. In evaluating the effect of the treatments were determined the germination percentage, mean germination time, germination speed index and relative frequency of germination. Scarification with sulfuric acid increased the germination of I. indivisa and I. purpurea seeds and the germination speed index of I. purpurea seeds. The hot water treatment was more effective in promoting germination of I. grandifolia seeds, and reduce the average time of germination of $\mathbf{I}$. grandifolia and I. purpurea seeds, so that in treatments for overcoming dormancy there are synchronization of the germination process.

Key words: morning glory, germination, vigor, weed.

\section{INTRODUÇÃO}

A dormência é considerada uma estratégia fundamental para espécies que sobrevivem por longos períodos de tempo no solo, a exemplo das infestantes, a qual é atribuída a vários mecanismos, dentre os quais estão a impermeabilidade do tegumento à água e a gases, imaturidade do embrião, presença de inibidores ou ausência de promotores, assim como exigências especiais de luz ou temperatura (VÁZQUEZ-YANES \& OROZCO-SEGOVIA, 1993; FERREIRA \& BORGHETTI, 2004).

A descontinuidade do processo de germinação em uma população de sementes, determinada pela dormência, permite a sobrevivência das espécies infestantes presentes nobanco desementes

IPrograma de Pós-graduação em Agronomia (PPGAG), Universidade Tecnológica Federal do Paraná (UTFPR), Campus Pato Branco, 85503-390, Pato Branco, PR, Brasil. E-mail: trezzi@utfpr.edu.br. *Autor para correspondência. Recebido 13.08.12 Aprovado 20.07.14 Devolvido pelo autor 11.09.14 CR-2012-0665.R7 
ao longo do tempo e também que a germinação ocorra em períodos, em que as condições de ambiente lhes são mais favoráveis (FINCH-SAVAGE \& LEUBNER-METZGER, 2006). Nesse sentido, o conhecimento dos fatores que propiciam a germinação das sementes e a emergência de plântulas daninhas do banco de sementes do solo poderia proporcionar ao agricultor um controle mais eficiente, dispensando o uso inapropriado de herbicidas em pós-emergência.

As plantas de Ipomoea spp., além de serem competidoras importantes com as de soja, são muito prejudiciais durante a colheita, em função do seu hábito de crescimento volúvel (KISSMANN \& GROTH, 1999). Nas sementes de espécies de Ipomoea, há diferentes fluxos de germinação durante a primavera e o verão, devido à sua dormência (AZANIA et. al., 2009), que é do tipo física, causada pela impermeabilidade do tegumento à água (CHANDLER et al., 1977), mas também pode haver diferentes tipos de dormência, o que justifica a realização de experimentos para determinar diferenças entre elas.

A eficácia de métodos para superação da dormência em espécies de Ipomoea é variável, sendo que o tratamento de sementes de Ipomoea com ácido sulfúrico tem proporcionado bons resultados em função da espessura do tegumento e período de exposição, a exemplo de I. hederacea (STOLLER \& WAX, 1974), I. obscura, I. aquatica e I. hederifolia (OGUNWENMO \& UGBOROGHO, 1999).

A identificação dos métodos de superação da dormência mais eficazes para as espécies $\boldsymbol{I}$. grandifolia, I. indivisa e I. purpurea em uma abordagem comparativa ainda não foi efetuada no Brasil, pois estas espécies estão distribuídas em muitos Estados brasileiros (FERREIRA \& BORGHETTI, 2004) e são as mais frequentes em áreas de soja do Sudoeste do Paraná.

Diante do exposto, no presente estudo, o objetivo foi selecionar métodos eficazes de superação da dormência nas sementes das espécies Ipomoea indivisa, I. grandifolia e I. purpurea e determinar como influenciam na cinética da germinação.

\section{MATERIAL E MÉTODOS}

O experimento foi conduzido no Laboratório de Sementes da Universidade Tecnológica Federal do Paraná, Campus de Pato Branco, utilizando-se sementes de Ipomoea coletadas em lavouras de soja transgênica, localizadas no município de Renascença, no Estado do Paraná.
O delineamento experimental utilizado foi o inteiramente casualizado, com os tratamentos distribuídos em esquema fatorial $3 \times 5$ (espécies de Ipomoea e tratamentos para superação de dormência), em cinco repetições. $\mathrm{Na}$ escarificação química, as sementes foram colocadas em ácido sulfúrico (98\%) (uma parte de semente para duas de ácido, em $\mathrm{m} / \mathrm{v}$ ) por 10 minutos, com agitação constante e, na sequência, realizou-se lavagem em água corrente; na escarificação mecânica, utilizou-se uma lixa de parede $\mathrm{n}^{\mathrm{o}} 100$ por um minuto. No tratamento com água quente, foram utilizados béqueres de $50 \mathrm{~mL}$ para acondicionar as sementes com água a $98^{\circ} \mathrm{C}$, por uma hora, não sendo realizada a manutenção da temperatura nesse período. No tratamento com escarificação mecânica + resfriamento, as sementes foram escarificadas como supracitado e, em seguida, mantidas em placas de Petri a $4^{\circ} \mathrm{C}$, por 72 horas.

Após o término de todos os tratamentos, prepararam-se placas de Petri com dois discos de papel toalha germitest, umedecidos com solução do fungicida triadimenol ( $150 \mathrm{~g}$ de equivalente ácido) a $0,4 \%$. Cada repetição constou de uma placa com 10 sementes, totalizando cinco placas e 50 sementes por tratamento, que, após tratadas, foram transferidas para uma câmara de crescimento a $35^{\circ} \mathrm{C}$ por 15 dias, pois esta temperatura proporcionou as maiores percentagens de germinação, na média das três espécies avaliadas, em teste efetuado previamente.

A avaliação da germinação foi efetuada diariamente, durante 15 dias, considerando-se como germinadas as sementes com comprimento de raiz superior a dois milímetros, baseando-se em experimento realizado por AZANIA et al. (2003). Os cálculos de porcentagem, tempo médio e frequência relativa de germinação foram realizados conforme fórmulas citadas por LABOURIAU \& VALADARES (1976), enquanto o índice de velocidade de germinação foi calculado de acordo com MAGUIRE (1962).

Aanálisedavariânciafoiprocedidapeloteste de $\mathrm{F}$ e as médias do fator quantitativo foram ajustadas ao modelo de regressão não-linear pela equação hipérbole retangular simples de dois parâmetros, com auxílio do programa computacional Sigmaplot 10.0.

\section{RESULTADOS E DISCUSSÃO}

As sementes das espécies de Ipomoea responderam de forma distinta aos métodos de superação da dormência, cuja germinação de I.indivisa e I. purpurea foi favorecida pela escarificação com ácido sulfúrico (Figuras 1A e C) e de I. grandifolia com água quente (Figura 1B). Os parâmetros e 


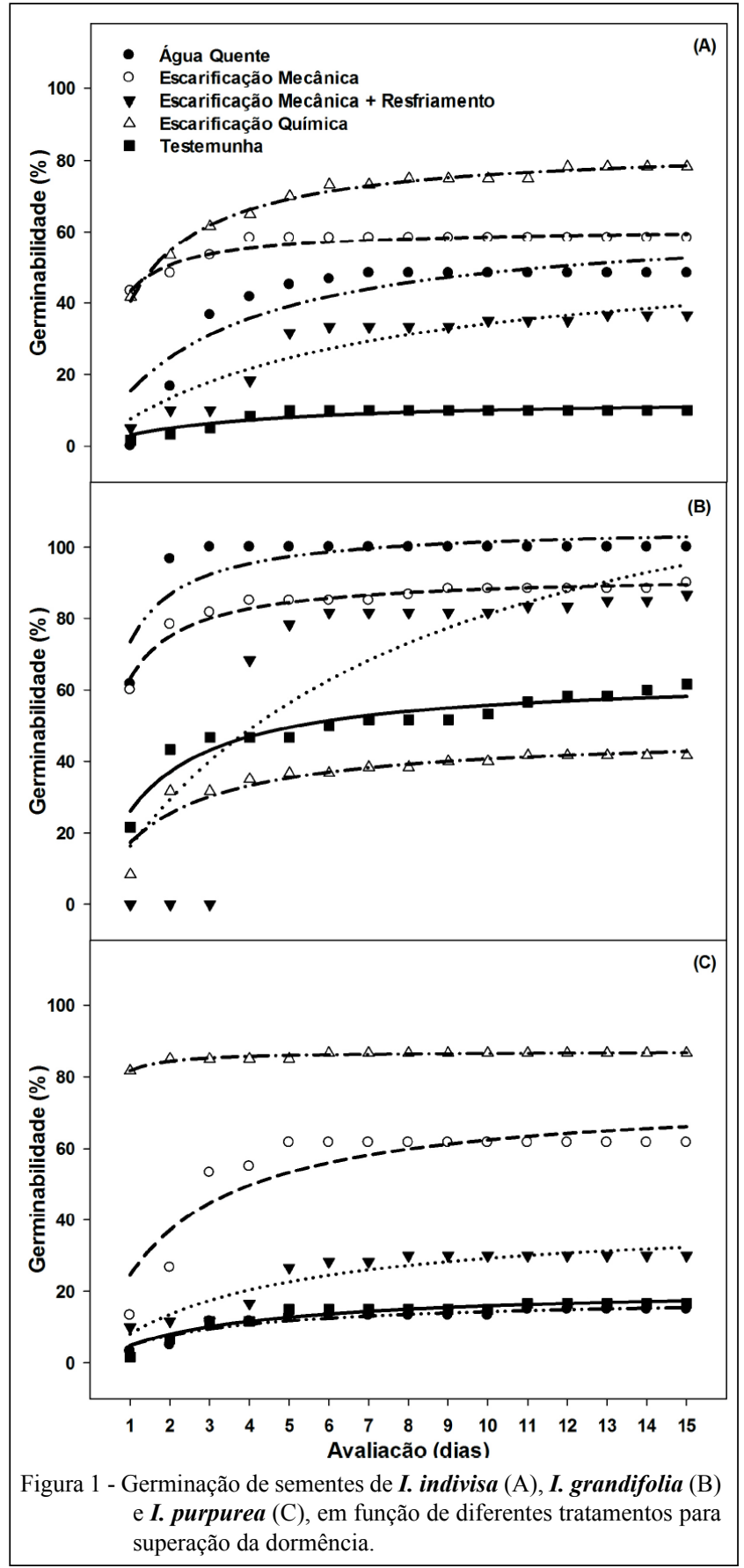

coeficientes de determinação das equações utilizadas para ajustar a relação entre porcentagem e tempo de germinação encontram-se na tabela 1 .

A escarificação química com ácido sulfúrico proporcionou aumento nos percentuais de germinação das sementes de I. indivisa e I. purpurea em 780 e $512 \%$, respectivamente, em relação à testemunha (Figuras 1A e C), cujo incremento também fora descrito em outros trabalhos científicos
(STOLLER \& WAX, 1974; HORAK \& WAX, 1991). Todavia, em I. grandifolia, a escarificação química reduziu em aproximadamente $32 \%$ a germinação máxima, quando comparado à testemunha (Figura 1B), resultados diferentes dos obtidos por AZANIA et al. (2003) que, trabalhando com período de exposição das sementes, similar ao do presente experimento, verificaram aumento de $60 \%$ na germinação.

A redução do percentual de germinação de sementes de determinadas espécies após o

Ciência Rural, v.45, n.2, fev, 2015. 
Tabela 1 - Parâmetros e coeficientes de determinação das equações utilizadas para ajustar a germinação, em relação ao tempo de avaliação de sementes de espécies de Ipomoea

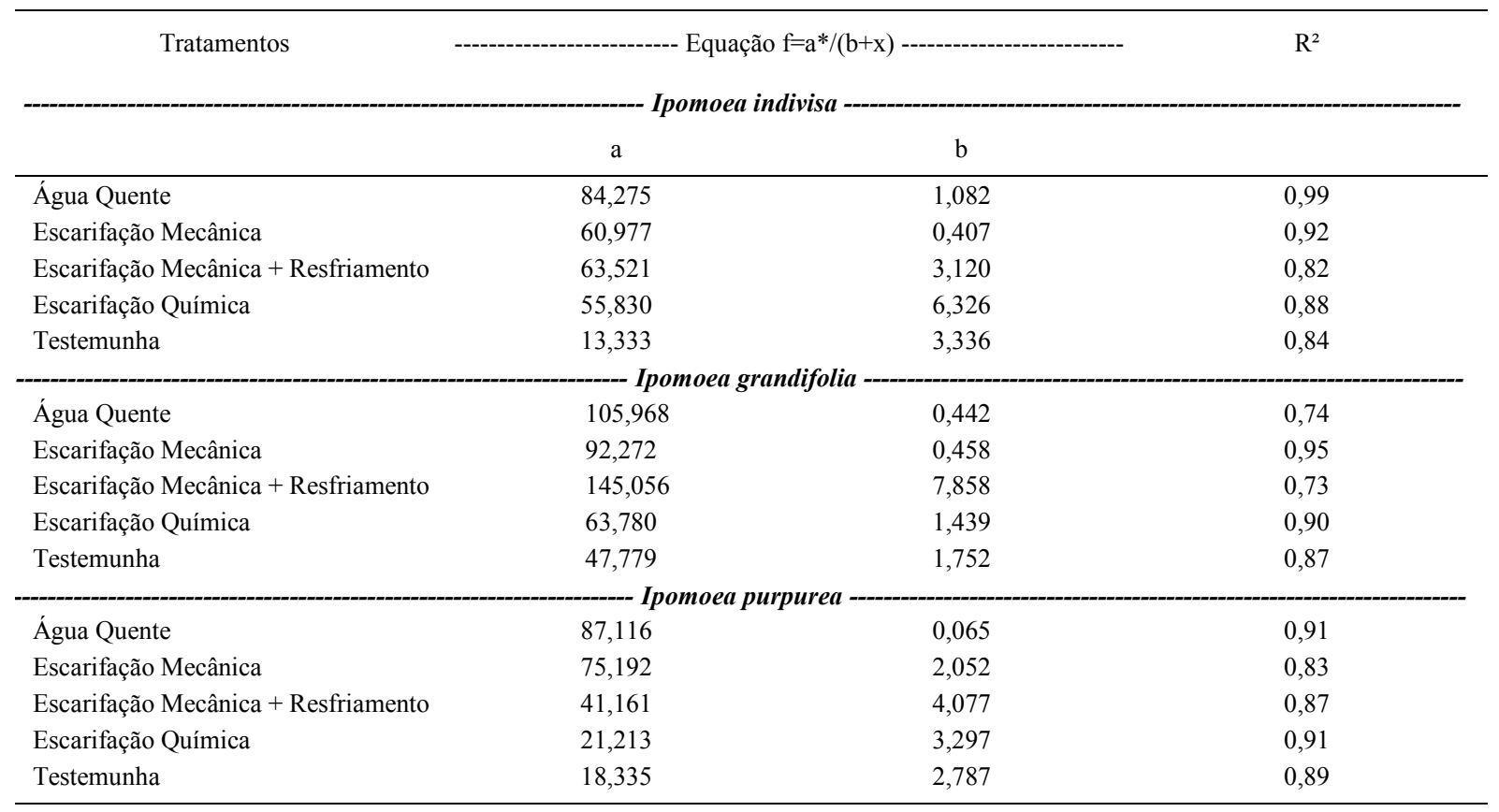

tratamento com ácido sulfúrico, como ocorreu no presente experimento com I. grandifolia, pode ser explicada pela menor concentração de substâncias que dificultam a embebição, na parede celular, visto que a impermeabilidade ocorre pela formação da camada paliçádica, composta por suberina, cutina e lignina (ROLSTON, 1978).

A escarificação mecânica também foi eficiente na superação da dormência, sendo o segundo método a proporcionar maior germinação nas sementes das espécies estudadas, chegando a atingir percentuais máximos de 90,62 e $58 \%$ em $\boldsymbol{I}$. grandifolia, I. purpurea I.indivisa, respectivamente. Para I. obscura, I. aquatica, I. hederifolia, I. asarifolia e I. involucrata, a escarificação mecânica também favoreceu a germinação (OGUNWENMO \& UGBOROGHO, 1999).

Ao trabalhar com diferentes tempos de escarificação mecânica, PINHEIRO (2010) obteve porcentagem de germinação em torno de $60 \%$ para I. indivisa e I. purpurea e de $80 \%$ para a I. triloba. Porém, AZANIA et al. (2003) verificaram que a escarificação mecânica com lixa não proporcionou melhoria na germinação das sementes de $\boldsymbol{I}$. grandifolia, I. hederifolia, I. quamoclit e I. nil (L.) Roth. A eficiência no processo de escarificação mecânica é dependente do tempo de exposição, intensidade da força aplicada sobre as sementes e homogeneidade da amostra, pois o atrito, no caso de sementes pequenas ou com tegumento menos lignificado, pode provocar rachaduras prejudiciais ao embrião e sua germinação.

A superação da dormência através do tratamento com água quente resultou em incrementos na germinação das sementes de $\boldsymbol{I}$. indivisa e I. grandifolia, da ordem de 480 e 162\% em relação à testemunha, respectivamente (Figuras $1 \mathrm{~A}$ e B), entretanto, o tratamento com água quente não influenciou positivamente na germinação de I. purpurea (Figura 1C). Efeito prejudicial na germinação de sementes de I. quamoclit, causado pela água quente $\left(98^{\circ} \mathrm{C}\right)$, em relação ao tratamento com água à temperatura ambiente $\left(26^{\circ} \mathrm{C}\right)$, foi observado por AZANIA et al. (2009), em qualquer dos períodos de embebição avaliados (entre 0,5 e 24 horas) e foi atribuído aos danos desse tratamento na qualidade das sementes dessa espécie.

Para a maioria das espécies cultivadas, a temperatura ótima encontra-se na faixa entre 15 e $30^{\circ} \mathrm{C}$ (MALAVASI, 1988). Para as espécies em estudo, foi observada redução de 3, 36 e 48\% na germinação das sementes de I. grandifolia, I. indivisa e I. purpurea, respectivamente, quando elas foram escarificadas mecanicamente e expostas ao frio, em relação às submetidas apenas à escarificação mecânica (Figuras 1A, B e C). A redução na germinação ocorreu, provavelmente, porque, em baixa temperatura, o 
metabolismo é reduzido e a semente necessita de mais tempo para germinar (AMARAL \& PAULILO, 1992), visto que são espécies nativas de regiões tropicais, o que foi confirmado pelos dados de tempo médio de germinação ( $t$ ) (Figura 2), em que o maior $t$ ocorreu no tratamento com resfriamento das sementes.

Em média, as sementes de $\boldsymbol{I}$. purpurea foram aquelas com menor $t$, seguida das de $\boldsymbol{I}$. indivisa e I. grandifolia (Figura 2), não havendo um tratamento que se destacasse para todas as espécies. $\mathrm{O}$ tratamento com escarificação mecânica + resfriamento nas sementes de I. grandifolia (Figura 2) promoveu o maior $t$, indicando provavelmente maior sensibilidade à temperatura que as das demais. Os menores valores de $t$ para as sementes de I. grandifolia e I. purpurea foram obtidos com água a $98^{\circ} \mathrm{C}$ e podem estar relacionados ao rápido processo de embebição, resultante da maior capacidade de rompimento de barreiras responsáveis pelo impedimento do processo germinativo.
As sementes com o maior índice de velocidade de germinação foram da I. grandifolia, no entanto, não houve diferença significativa dos tratamentos em relação à testemunha, exceto para a escarificação química em I. purpurea, que promoveu incremento de $620 \%$ nesse índice (Figura 3). Apenas na espécie I. grandifolia, o índice de velocidade de germinação do tratamento com escarificação mecânica foi superior aos demais, o qual superou em 181 e $567 \%$ os valores das espécies I. indivisa I. purpurea, respectivamente (Figura 3), no entanto, nas demais comparações, não ocorreram diferenças significativas.

A maior frequência de germinação para as sementes de I. indivisa ocorreu com a escarificação mecânica, atingindo $82 \%$ no primeiro dia, seguido pela escarificação química, com $56 \%$, enquanto, na testemunha, as sementes ainda não tinham germinado, atingindo a frequência máxima de $50 \%$, apenas no quarto dia. Para sementes de I. grandifolia (Figura 4B), a água quente proporcionou frequência de $87 \%$ no primeiro dia, seguido da escarificação mecânica,

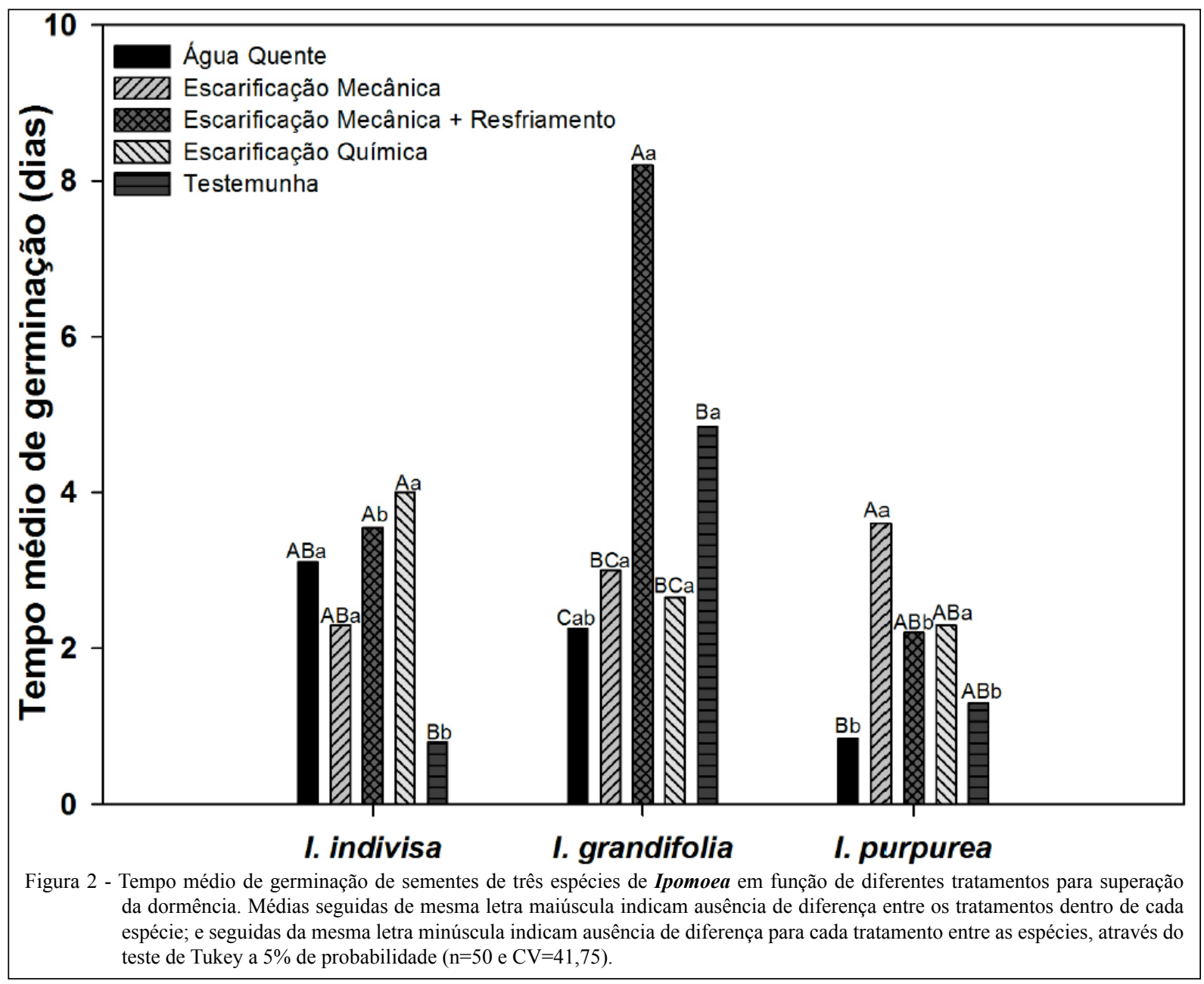

Ciência Rural, v.45, n.2, fev, 2015. 


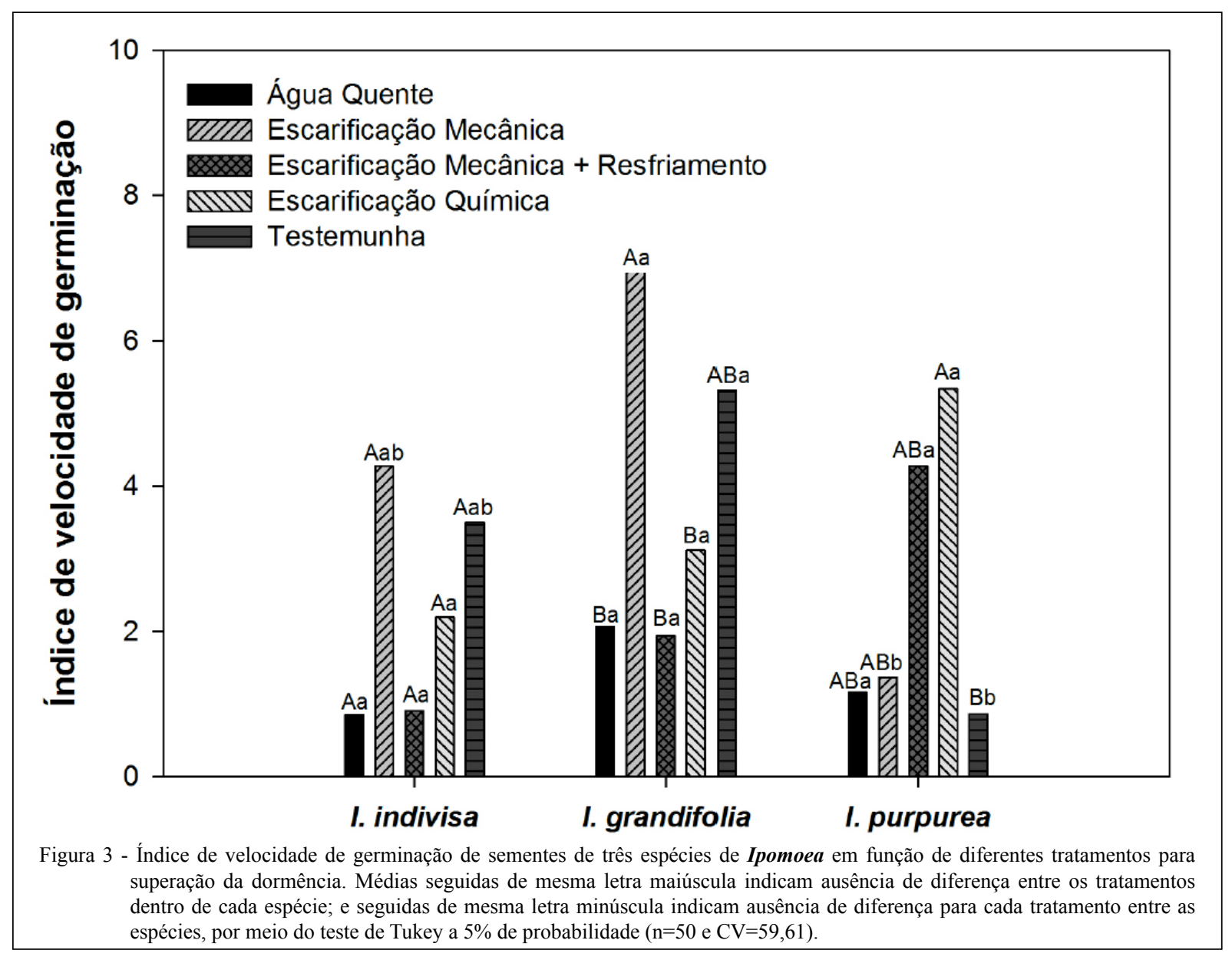

com $72 \%$, enquanto, na testemunha, constatou-se apenas $47 \%$ de germinação.

As sementes de $\boldsymbol{I}$. purpurea alcançaram $92 \%$ de germinação no primeiro dia com a escarificação química e a testemunha apenas $8 \%$ (Figura $4 \mathrm{C}$ ), sendo as maiores frequências de germinação nas sementes da testemunha verificadas no primeiro, segundo e quarto dias, para I. grandifolia, I. purpurea e $\boldsymbol{I}$. indivisa, respectivamente (Figura 4).

As variações observadas nas frequências de germinação, em função dos tratamentos de superação da dormência das sementes das espécies de Ipomoea (Figura 4), confirmam a existência de sinais que se sobrepõem ao estímulo natural da germinação (LABOURIAU, 1983). Nesses casos, manifestam-se padrões em que grande parte das sementes germina de forma concentrada em curto espaço de tempo, sugerindo que a germinação responde a um estímulo ou mecanismo (FERREIRA \& BORGHETTI, 2004).

Nas sementes da testemunha, a germinação se distribui ao longo do tempo, ou seja, o sincronismo é inferior ao observado quando as sementes foram submetidas aos tratamentos de superação de dormência. Também, em laboratório, as espécies I. grandifolia e I. indivisa expressaram fluxos de germinação por períodos mais longos de tempo, em relação à I. purpurea. Isso, se confirmado a campo, é importante para a escolha de herbicidas préemergentes, que são eficientes em controlar e há maior persistência para as espécies com fluxos de germinação de sementes por períodos de tempo mais longos.

A identificação dos tratamentos mais eficientes para as sementes de cada espécie pode ser correlacionada com fatores ambientais determinantes do padrão germinativo, como, por exemplo, a resposta positiva à elevada temperatura em I. grandifolia. Além disso, em trabalhos de pesquisa, os tratamentos mais eficazes são importantes para aumentar a uniformidade e os percentuais de germinação.

\section{CONCLUSÃO}

A escarificação com ácido sulfúrico é indicada para a superação da dormência das sementes 


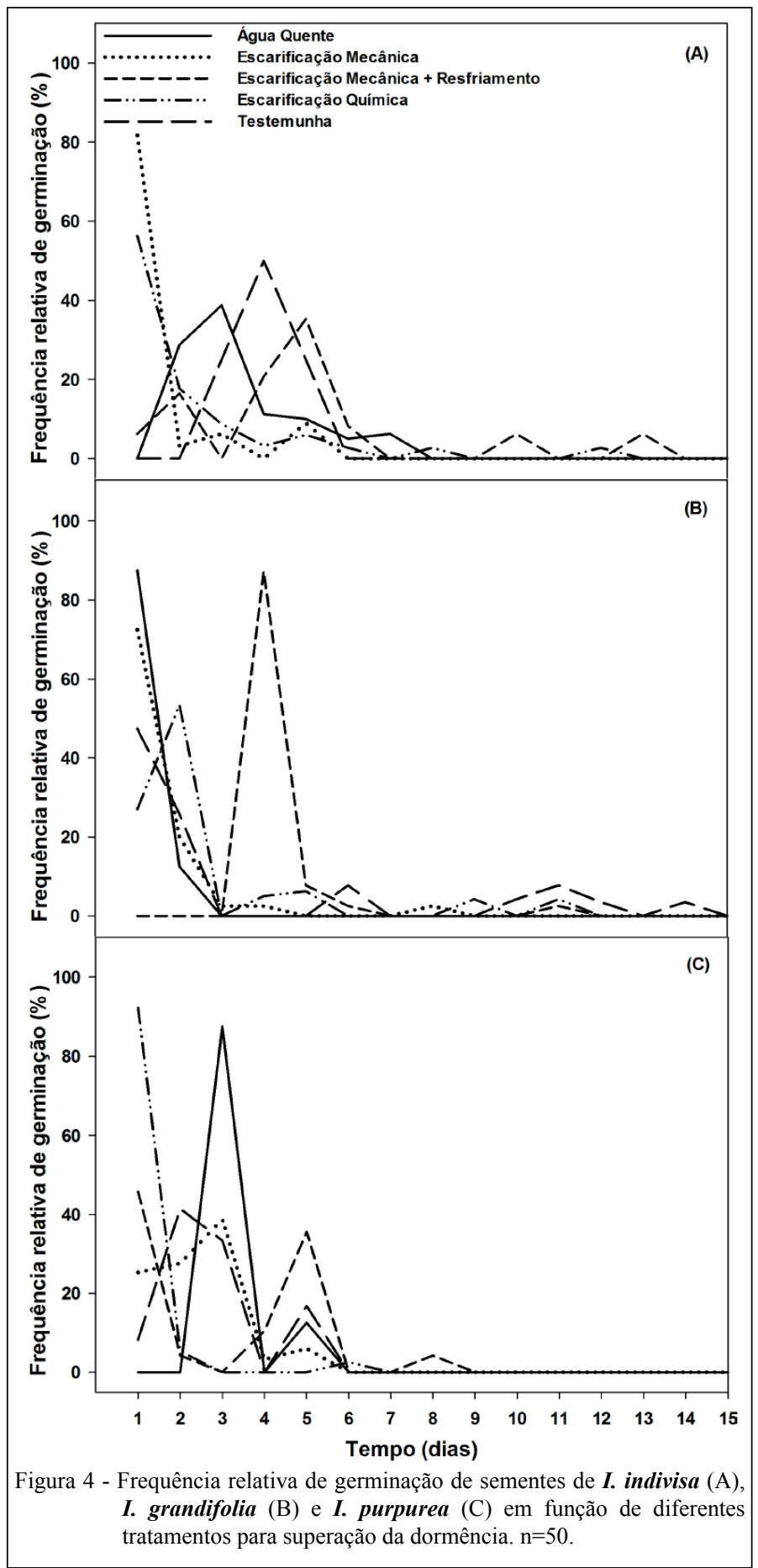

de I. indivisa e I. purpurea, enquanto o tratamento com água quente é o mais eficiente em promover a germinação de I. grandifolia.

\section{AGRADECIMENTOS}

À Coordenação de Aperfeiçoamento de Pessoal de Nível Superior (CAPES) e ao Conselho Nacional de
Desenvolvimento Científico e Tecnológico $(\mathrm{CNPq})$, pela concessão de bolsas de estudos, e à Universidade Tecnológica Federal do Paraná (UTFPR), pela concessão de recursos financeiros.

\section{REFERÊNCIAS}

AMARAL, L.I.V.; PAULILO, M.T.S. Efeito da luz, temperatura, reguladores de crescimento e nitrato de potássio na germinação de

Ciência Rural, v.45, n.2, fev, 2015. 
Miconia cinnamomifolia (DC) Naudim. Insula, v.21, n.1, p.5986, 1992. Disponível em: <https://periodicos.ufsc.br/index.php/ insula/article/view/22252/20173>. Acesso em: 17 ago. 2014.

AZANIA, A.A.P.M. et al. Métodos de superação de dormência em sementes de Ipomoea e Merremia. Planta daninha, v.21, n.2, p.203-209, 2003. Disponível em: <http://dx.doi.org/10.1590/ S0100-83582003000200005>. Acesso em: 17 ago. 2014. doi: $10.1590 / \mathrm{S} 0100-83582003000200005$

AZANIA, C.A.M. et al. Superação da dormência de sementes de corda-de-viola (Ipomoea quamoclit e I. hederifolia). Planta daninha, v.27, n.1, p.23-27, 2009. Disponível em: <http://dx.doi. org/10.1590/S0100-83582009000100004>. Acesso em: 17 ago. 2014. doi: 10.1590/S0100-83582009000100004.

CHANDLER, J.M. et al. Purple moonflower: emergence, growth, reproduction. Weed Science, v.25, n.2, p.163-167, 1977. Disponível em: <http://www.jstor.org/stable/4042829>. Acesso em: 17 ago. 2014

FERREIRA, A.G.; BORGHETTI, F. Germinação: do básico ao aplicado. Porto Alegre: Artmed, 2004. 323p.

FINCH-SAVAGE, W.E.; LEUBNER-METZGER, G.L. Seed dormancy and the control of germination. New Phytologist, v.171, n.3, p.501-523, 2006. Disponível em: <http://onlinelibrary.wiley. com/doi/10.1111/j.1469-8137.2006.01787.x/pdf>. Acesso em: 17 ago. 2014. doi: 10.1111/j.1469-8137.2006.01787.x.

HORAK, M.J.; WAX, L.M. Germination and seedling development of bigroot morningglory (Ipomoea pandurata). Weed Science, v.39, n.3, p.390-396, 1991. Disponível em: <http://www.jstor.org/ stable/4044968>. Acesso em 17 ago. 2014.

KISSMANN, K.G.; GROTH, D. Plantas infestantes e nocivas. 2.ed. São Paulo: BASF, 1999. Tomo II, 978p.

LABOURIAU, L.G. A germinação das sementes. Washington: Secretaria Geral da OEA, 1983. 174p.
LABOURIAU, L.G.; VALADARES, M.E.B. On the germination of seeds of Calotropis procera (Ait.) Ait.f. Anais da Academia Brasileira de Ciências, v.48, n.2, p.263-284, 1976.

MAGUIRE, J.D. Speeds of germination-aid selection and evaluation for seedling emergence and vigor. Crop Science, v.2, n.2, p.176-177, 1962. Disponível em: <https://www.crops.org/ publications/cs/abstracts/2/2/CS0020020176>. Acesso em: 17 ago. 2014. doi:10.2135/cropsci1962.0011183X000200020033x.

MALAVASI, M.M. Germinação de sementes. In: PIÑARODRIGUES, F.C. (Coord.). Manual de análise de sementes florestais. Campinas: Fundação Cargill, 1988. p.25-40.

OGUNWENMO, K.; UGBOROGHO, R.E. Effects of chemical and mechanical scarification on seed germination of five species of Ipomoea (Convolvulaceae). Bulletin Society Broteriana, v.69, n.1, p.147-162, 1999. Disponível em: <http://cat.inist.fr/?aModele $=$ afficheN\&cpsidt $=20052465>$. Acesso em: 17 ago. 2014 .

PINHEIRO, R. T. Superação de dormência de sementes e controle químico de cordas-de-viola (Ipomoea spp.) em soja resistente ao glifosato. 2010. 67f. Dissertação (Mestrado em Agronomia) - Universidade Federal de Santa Maria, Santa Maria, RS.

ROLSTON, M.P. Water impermeable seed dormancy. Botanical Review, v.44, n.3, p.365-396, 1978. Disponível em: <http:// link.springer.com/article/10.1007/BF02957854>. Acesso em: 17.08.2014. doi: 10.1007/BF02957854

STOLLER, E.W.; WAX, L.M. Dormancy changes and fate of some annual weed seeds in the soil. Weed Science, v.22, n.2, p.151155, 1974. Disponível em: <http://www.jstor.org/stable/4042527>. Acesso em: 17.08.2014.

VÁZQUEZ-YANES, C.; OROZCO-SEGOVIA, A. Pattern of seed longevity and germination in the tropical rain forest. Annual Review of Ecology and Systematics, v.24, n.1, p.69-87, 1993. Disponível em: <http://www.jstor.org/stable/2097173>. Acesso em: 17.08.2014 